\title{
Antitumor effect of metformin on cholangiocarcinoma: In vitro and in vivo studies
}

\author{
TAKAYUKI FUJIMORI $^{1}$, KIYOHITO KATO ${ }^{1}$, SHINTARO FUJIHARA ${ }^{1}$, HISAKAZU IWAMA ${ }^{2}$, \\ TAKUMA YAMASHITA ${ }^{1}$, KIYOYUKI KOBAYASHI ${ }^{1}$, HIDEKI KAMADA ${ }^{1}$, ASAHIRO MORISHITA ${ }^{1}$, \\ HIDEKI KOBARA $^{1}$, HIROHITO MORI ${ }^{1}$, KEIICHI OKANO ${ }^{3}$, YASUYUKI SUZUKI ${ }^{3}$ and TSUTOMU MASAKI $^{1}$ \\ ${ }^{1}$ Department of Gastroenterology and Neurology, ${ }^{2}$ Life Science Research Center and ${ }^{3}$ Department of Gastroenterological \\ Surgery, Kagawa University, Faculty of Medicine, Graduate School of Medicine, Miki-cho, Kita-gun, Kagawa 761-0793, Japan
}

Received June 14, 2015; Accepted July 31, 2015

DOI: $10.3892 / o r .2015 .4284$

\begin{abstract}
Cholangiocarcinoma (CCA) is the most common biliary malignancy and the second most common hepatic malignancy after hepatocellular carcinoma (HCC). Treatment with the anti-diabetic drug metformin has been associated with reduced cancer incidence in patients with type 2 diabetes. Thus, the present study evaluated the effects of metformin on human CCA cell proliferation in vitro and in vivo and identified the microRNAs associated with its antitumor effects. Metformin inhibited the proliferation of the CCA cell lines HuCCT-1 and TFK-1 and blocked the $\mathrm{G}_{0}$ to $\mathrm{G}_{1}$ cell cycle transition, accompanied by AMP kinase pathway activation. Metformin treatment also led to marked decreases in cyclin D1 and cyclin-dependent kinase (Cdk) 4 protein levels and retinoblastoma protein phosphorylation. However, this drug did not affect $\mathrm{p} 27^{\mathrm{kip}}$ protein expression. In addition, it reduced the phosphorylation of Axl, EphA10, ALK and PYK, as well as tumor proliferation in athymic nude mice with xenograft tumors. Furthermore, it markedly altered microRNA expression. These findings suggest that metformin may have clinical use in the treatment of CCA.
\end{abstract}

\section{Introduction}

Cholangiocarcinoma (CCA) is the most common biliary malignancy and the second most common hepatic malignancy after hepatocellular carcinoma (HCC) (1). It accounts for 3\% of all gastrointestinal tumors, and its overall incidence has increased in the last few decades (2). Hepatobiliary cancers

Correspondence to: Professor Tsutomu Masaki, Department of Gastroenterology and Neurology, Kagawa University, Faculty of Medicine, Graduate School of Medicine, 1750-1 Ikenobe, Miki-cho, Kita-gun, Kagawa 761-0793, Japan

E-mail: tmasaki@med.kagawa-u.ac.jp

Key words: cholangiocarcinoma, microRNAs, metformin, cell cycle, cyclin D1 are associated with a poor prognosis, as many patients with biliary tract cancers present with advanced disease. The percentage of patients who survive to 5 years after diagnosis has not improved during this time period and has remained at $10 \%(3,4)$.

Metformin is an oral biguanide drug used to treat type 2 diabetes (5). This drug lowers hyperglycemia via the inhibition of hepatic glucose production. A recent epidemiologic survey indicated that metformin use was associated with reduced cancer incidence in patients with type 2 diabetes $(6,7)$. The anticarcinogenic activity of metformin has been attributed to several mechanisms, including the activation of the LKB1/AMPK pathway, induction of cell cycle arrest and/or apoptosis, inhibition of protein synthesis, inhibition of the unfolded protein response, activation of the immune system, and potential eradication of cancer stem cells (8). LKB1/AMPK pathway activation inhibits mammalian target of rapamycin (mTOR), which negatively affects protein synthesis in cancer cells (8). Metformin has been demonstrated to inhibit the proliferation of various cancer cell types, including prostate (5), breast (9), and colon (10) cancer cells.

Several in vitro and in vivo studies have indicated that metformin inhibits the growth of gastric (11), esophageal $(12,13)$, and hepatocellular (14) carcinoma cells. However, less is known regarding the antitumor effects of metformin on CCA cells and the microRNAs (miRNA) associated with these effects. Thus, the present study evaluated the effects of metformin on the growth of CCA cell lines, its mechanism of action, and the miRNAs associated with its antitumor effect.

\section{Materials and methods}

Reagents. Metformin (1,1-dimethylbiguanide monohydrochloride) was purchased from Astellas Pharma (Tokyo, Japan); all other chemicals were obtained from Sigma Chemical (Tokyo, Japan).

Cell culture. The two human CCA cell lines (TFK-1 and HuCCT-1) were included in this study. TFK-1 was obtained from the Riken Cell Bank (Tsukuba, Japan), and HuCCT-1 was obtained from the Japanese Cancer Research Resources Bank (Osaka, Japan). 
All cells were grown in RPMI-1640 (Gibco-Invitrogen, Carlsbad, CA, USA), supplemented with $10 \%$ fetal bovine serum (FBS) and penicillin-streptomycin $(9,100 \mathrm{mg} / \mathrm{l}$; Invitrogen) at $37^{\circ} \mathrm{C}$ in a humidified atmosphere that contained $5 \% \mathrm{CO}_{2}$.

Cell proliferation assay. A Cell Counting Kit-8 (CCK-8) was purchased from Dojindo Laboratories (Kumamoto, Japan) and used to evaluate cell proliferation, according to the manufacturer's instructions. Briefly, $5 \times 10^{3}$ cells were seeded into each well of a 96-well plate and cultured in $100 \mu \mathrm{l}$ of RPMI-1640 supplemented with $10 \%$ FBS. After $24 \mathrm{~h}$, metformin $(0,1,5$, or $10 \mathrm{mM}$ ) was added to each well, and the cells were cultured for an additional $72 \mathrm{~h}$. CCK-8 reagent $(10 \mu \mathrm{l})$ was added to each well, and the plates were incubated at $37^{\circ} \mathrm{C}$ for $3 \mathrm{~h}$. The absorbance of each well was measured at $450 \mathrm{~nm}$ using a microplate reader.

Preparation of cell lysates. Cell lysates were prepared as previously described at $4^{\circ} \mathrm{C}(15)$. Protein concentrations were measured using a dye-binding protein assay based on the Bradford method (16).

Gel electrophoresis and western blotting. HuCCT-1 cells $\left(1.0 \times 10^{6} / \mathrm{dish}\right)$ were seeded in $100-\mathrm{mm}$ culture dishes and cultured for $24 \mathrm{~h} ; 10 \mathrm{mmol} / \mathrm{l}$ metformin was added, and the cells were further cultured for 24-48 h. The cells were lysed in protease-inhibitor cocktail ('Complete' protease inhibitor mixture; iNtRON Biotechnology, Sungnam, Korea) on ice for $20 \mathrm{~min}$. Suspensions of lysed cells were centrifuged at $13,000 \mathrm{x} \mathrm{g}$ at $4^{\circ} \mathrm{C}$ for $5 \mathrm{~min}$; supernatants that contained soluble cellular proteins were collected and stored at $-80^{\circ} \mathrm{C}$ until use. Protein concentrations were measured using a Nanodrop 2000 fluorospectrometer (Thermo Scientific Corporation, USA). Protein aliquots $(1-10 \mu \mathrm{g})$ were resuspended in sample buffer and separated on $10 \%$ Tris-glycine gradient gels via SDS-PAGE (17). The proteins were subsequently transferred to nitrocellulose membranes. After blocking, the membranes were incubated with primary antibodies followed by horseradish peroxidase (HRP)-conjugated secondary antibodies (18).

Primary antibodies used for western blot analyses were obtained from the following sources: $\beta$-actin antibody was obtained from Sigma-Aldrich (St. Louis, MO, USA); cyclin D1 and cyclin $\mathrm{E}$ antibodies were obtained from Thermo Fisher Scientific (Waltham, MA, USA); Cdk6, Cdk2, and Cdk4 antibodies were obtained from Santa Cruz Biotechnology (Santa Cruz, CA, USA); phosphorylated retinoblastoma protein and $\mathrm{p} 27^{\mathrm{kip} 1}$ antibodies were obtained from $\mathrm{BD}$ Biosciences Pharmingen (San Jose, CA, USA); and AMPKa and phospho-AMPK $\alpha$ antibodies were obtained from Cell Signaling Technology (Danvers, MA, USA). Secondary antibodies included HRP-linked anti-mouse and anti-rabbit IgG antibodies (1:2,000; GE Healthcare, UK).

Immunoreactive proteins were visualized with an enhanced chemiluminescence detection system (Perkin-Elmer Co., Waltham, MA, USA) on X-ray film.

Flow cytometry. To evaluate the mechanism of growth inhibition by metformin, cell cycle profiles were analyzed after metformin treatment. HuCCT-1 cells $\left(1.0 \times 10^{6}\right.$ cells in a $100-\mathrm{mm}$ diameter dish) were treated with or without $10 \mathrm{mmol} / 1$ metformin for 24-48 h. Cell cycle progression was analyzed by measuring the amount of propidium iodide (PI)-labeled DNA in the ethanol-fixed cells. The fixed cells were washed with PBS and then stored at $-20^{\circ} \mathrm{C}$ until flow cytometric analysis. On the day of analysis, the cells were washed with cold PBS, suspended in $100 \mu \mathrm{l}$ of PBS plus $10 \mu \mathrm{l}$ of RNase A (250 $\mu \mathrm{g} /$ $\mathrm{ml}$ ) and incubated for $30 \mathrm{~min}$. A volume of $110 \mu \mathrm{l}$ of PI stain $(100 \mu \mathrm{g} / \mathrm{ml})$ was added to each suspension, and the cells were incubated at $4^{\circ} \mathrm{C}$ for at least $30 \mathrm{~min}$ prior to analysis. Flow cytometry was performed using a Cytomics FC 500 flow cytometer (Beckman Coulter) with an argon laser (488 nm). The percentages of cells in the different cell cycle phases were analyzed using FlowJo software (TreeStar, Ashland, OR, USA). All experiments were performed in triplicate.

Antibody arrays of phosphorylated receptor tyrosine kinase $(p-R T K)$. Human phospho-RTK was assayed using Human Phospho-RTK Array kits (R\&D Systems, Minneapolis, MN, USA), according to the manufacturer's instructions. Briefly, p-RTK array membranes were blocked with 5\% BSA/TBS $(0.01 \mathrm{M}$ Tris- $\mathrm{HCl}, \mathrm{pH}$ 7.6) for $1 \mathrm{~h}$ and incubated with $2 \mathrm{ml}$ of lysate, which was prepared from cell lines after normalization to ensure equal protein amounts. After 3 washes for $10 \mathrm{~min}$ each with TBS plus $0.1 \% \mathrm{v} / \mathrm{v}$ Tween- 20 and 2 washes for 10 min with TBS alone to remove unbound materials, the membranes were incubated with anti-phospho-tyrosine-HRP antibody for $2 \mathrm{~h}$ at room temperature. The unbound HRP antibody was washed out with TBS plus $0.1 \%$ Tween-20. Finally, each array membrane was exposed to X-ray film using a chemiluminescence detection system (Perkin-Elmer Co.). The immunoreactive band density obtained via this array was analyzed by densitometric scanning (TIc scanner; Shimizu Co., Ltd., Kyoto, Japan).

Angiogenic profile analysis using an antibody array. A RayBio Human Angiogenesis Antibody Array (RayBiotech, Inc.) was used according to the manufacturer's protocol. This method comprised a dot-based assay that enabled the detection and comparison of 20 angiogenesis-specific cytokines. Each array membrane was exposed to X-ray film using a chemiluminescence detection system (Perkin-Elmer Co.). The immunoreactive band density obtained via this array was analyzed by densitometric scanning (TIc scanner; Shimizu Co., Ltd.).

Xenograft model analysis. Animal experiments were performed according to the guidelines of the Committee on Experimental Animals of Kagawa University, Kagawa, Japan.

Thirty male athymic mice (BALB/c-nu/nu; 6 weeks old; 20-25 g) were purchased from Japan SLC, Inc., and maintained under specific pathogen-free conditions using a laminar airflow rack. The mice had continuous free access to sterilized ( $\gamma$-irradiated) food (CL-2; CLEA Japan, Inc.) and autoclaved water. Each mouse was subcutaneously inoculated with HuCCT-1 cells $\left(5 \times 10^{6}\right.$ cells/animal) in the flank. One week later, the xenografts were identifiable as masses with a maximal diameter $>6 \mathrm{~mm}$. The animals were randomized to treatment with metformin or PBS. The metformin group 
HuCCT-1

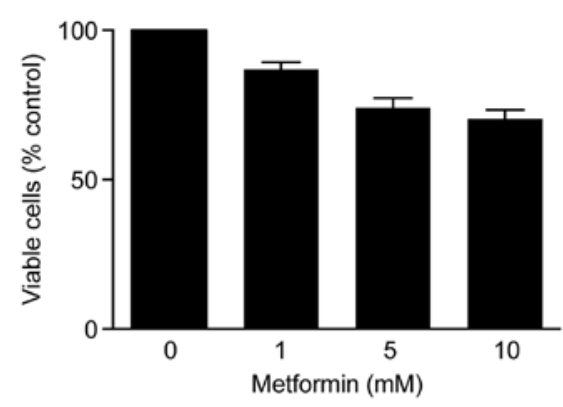

HuCCT-1

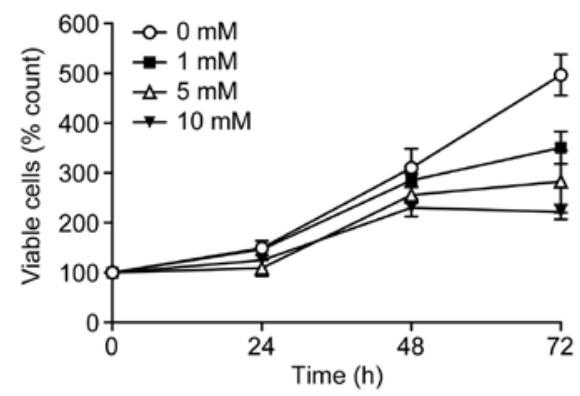

TFK-1

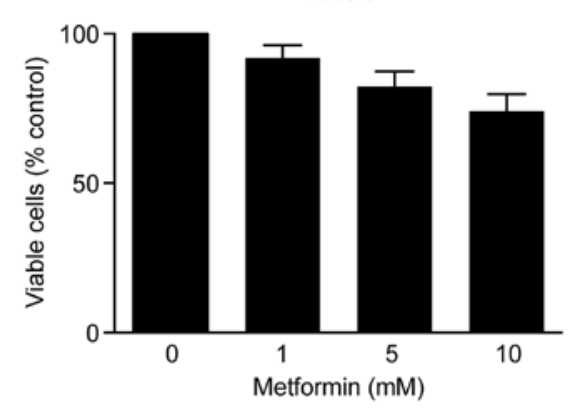

TFK-1

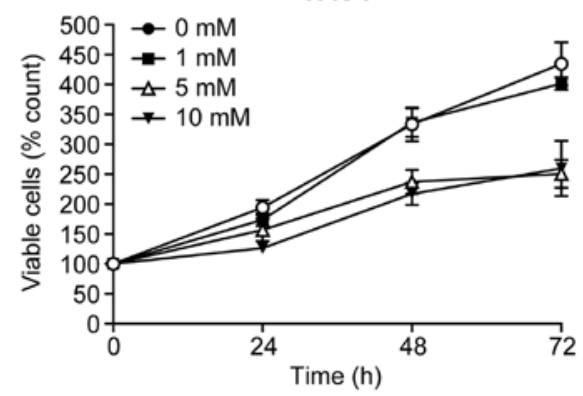

Figure 1. Metformin inhibits the proliferation of cholangiocarcinoma cells. HuCCT-1 and TFK-1 cells were seeded in 96 -well plates. After $24 \mathrm{~h}$, metformin (1, 5 , and $10 \mathrm{mmol} / \mathrm{l}$ ) or vehicle was added to the culture medium; $24 \mathrm{~h}$ later, the cells were counted via CCK assay. HuCCT-1 and TFK-1 cells (5,000/well) were seeded in 96-well plates, and metformin was added as previously described. Cell viability was assayed daily from 0 to $72 \mathrm{~h}$. The viability of the metformintreated cells was significantly different from that of the control cells $(\mathrm{p}<0.05)$.

A

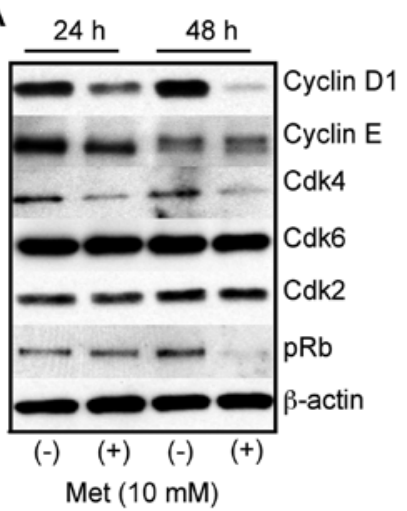

B

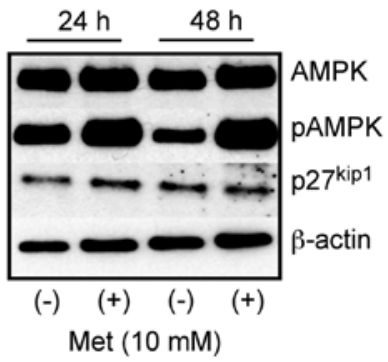

Figure 2. Expression of (A) cyclin D1, Cdk4, Cdk6, cyclin E, Cdk2, phosphorylated Rb (pRb), (B) AMPK, p-AMPK, and p2 $7^{\text {kipl }}$ in HuCCT-1 cells at 24 and $48 \mathrm{~h}$ after the addition of $10 \mathrm{mmol} / \mathrm{l}$ metformin. Protein expression was assayed by western blotting.

was intraperitoneally (i.p.) injected five times per week with $2 \mathrm{mg} / \mathrm{kg}$ body weight per day of metformin for 31 days; the control group was administered PBS alone for 31 days. The tumor growth was monitored daily by the same investigators (T. Fujimori and T. Masaki), and the tumor size was measured weekly by measuring the 2 greatest perpendicular dimensions. The tumor volume $\left(\mathrm{mm}^{3}\right)$ was calculated as the tumor length $(\mathrm{mm}) \mathrm{x}$ tumor width $(\mathrm{mm})^{2} / 2$ (19). All animals were sacrificed on day 31 after treatment, and all animals had survived during this period. Between-group differences in tumor growth were analyzed by two-way ANOVA.

Analysis of miRNA arrays. Total RNA was extracted from tumor samples and cancer cell lines using a miRNeasy
Mini kit (Qiagen, Hilden, Germany) according to the manufacturer's instructions. RNA samples typically exhibited $\mathrm{A}_{260 / 280}$ ratios of between 1.9 and 2.1, as determined using an Agilent 2100 Bioanalyzer (Agilent Technologies, Santa Clara, CA, USA).

After RNA measurements were performed with an RNA 6000 Nano kit (Agilent Technologies), the samples were labeled using a miRCURYHy3/Hy5 Power Labeling kit and subsequently hybridized to a human miRNA Oligo chip (v.14.0; Toray Industries, Tokyo, Japan). The chips were scanned with a 3D Gene Scanner 3000 (Toray Industries), and the results were analyzed using 3D-Gene extraction version 1.2 software (Toray Industries). Differences in miRNA expression between the metformin-treated and control samples were assessed by analyzing the raw data using GeneSpringGX v10.0 (Agilent Technologies). The samples were first normalized to 28S RNA expression and were then baseline-corrected to the median of all samples.

Replicate data were consolidated into 2 groups, metformin-treated and control cells and were organized using the hierarchical clustering and ANOVA functions in GeneSpring software. Hierarchical clustering was performed using the use clustering function (condition tree) and Euclidean correlation as a distance metric. Two-way ANOVA and asymptotic p-value computation without error correction for the samples were performed to determine the miRNAs that most prominently varied across the groups. The p-value cut-off was set to 0.01 . Only changes $>50 \%$ for at least one of the time-points for each sample were considered significant. All analyzed data were scaled by global normalization. The significance of differentially expressed miRNAs was analyzed the using Student's t-test. 

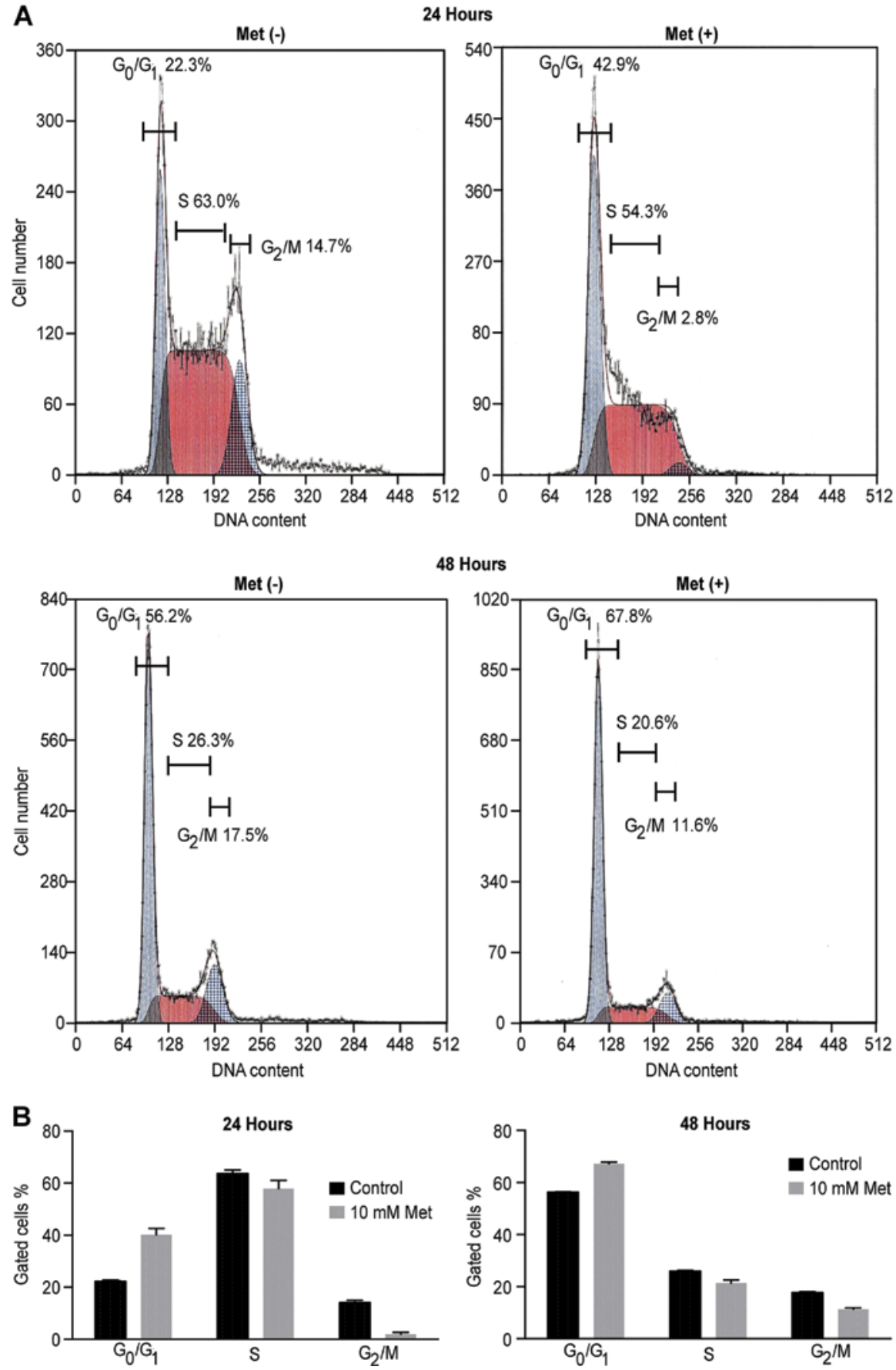

Figure 3. (A) Flow cytometric analysis of proliferating HuCCT-1 cells at 24 and $48 \mathrm{~h}$ after the addition of $10 \mathrm{mmol} / 1 \mathrm{metformin}$ (Met). (B) Metformin blocked the cell cycle at $\mathrm{G}_{0}-\mathrm{G}_{1}$. The results are representative of 3 independent experiments.

Statistical analyses. All statistical analyses were performed using computer assisted JMP 9.0 (SAS Institute, Cary, NC, USA). Paired analyses between groups used t-tests. A p-value of $<0.05$ was considered significant.

\section{Results}

Metformin inhibits the proliferation of human CCA cells. The effects of metformin on the proliferation of two CCA cell lines, HuCCT-1 and TFK-1, were evaluated. Cells were grown in $10 \%$ FBS and treated with $0,1,5$, or $10 \mathrm{mmol} / 1$ metformin for $72 \mathrm{~h}$. Metformin demonstrated a strong, dose-dependent inhibition of cell proliferation in all CCA cell lines tested (Fig. 1).
Metformin affects cell cycle-regulatory proteins in the HuCCT-1 cells. The effects of metformin on the expression of various cell cycle-related molecules in the HuCCT-1 cells were evaluated by western blotting. Cells were treated with 0 or $10 \mathrm{mmol} / \mathrm{l}$ metformin for $24-48 \mathrm{~h}$. The most marked metformin-associated change was the loss of cyclin D1, a key protein implicated in the transition from the $G_{0}$ to $G_{1}$ phase, which exhibited a time-dependent reduction (Fig. 2A). Metformin treatment also resulted in a progressive decrease in phosphorylated $\mathrm{Rb}$. Assays of the expression of other proteins associated with the $\mathrm{G}_{0}$ to $\mathrm{G}_{1}$ transition indicated that $\mathrm{Cdk} 4$, the catalytic subunit of cyclin D1, was decreased at $24-48 \mathrm{~h}$ after the addition of metformin (Fig. 2A). Additionally, increased 


\begin{tabular}{|c|c|c|c|c|c|c|c|c|c|c|c|}
\hline $\begin{array}{c}\text { Aeference } \\
\text { spots }\end{array}$ & & & & & & & & & & & \\
\hline EGF R & ErbB2 & ErbB3 & ErbB4 & FGF R1 & FGF R2 $\alpha$ & FGF R3 & FGF R4 & Insulin R & IGF-1 R & Axl & Dtk \\
\hline Mer & HGF R & MSP R & PDGF R $\alpha$ & PDGF R & SCF R & Flt-3 & M-CSF R & C-Ret & ROR1 & ROR2 & Tie-1 \\
\hline Tie-2 & TrkA & TrkB & TrkC & VEGF R1 & VEGF R2 & VEGF R3 & MuSK & EphA1 & EphA2 & EphA3 & EphA4 \\
\hline $\begin{array}{c}\text { EphA6 } \\
\text { EphA7 }\end{array}$ & EphB1 & EphB2 & EphB4 & EphB6 & ALK & DDR1 & DDR2 & EphA5 & EphA10 & \\
\hline $\begin{array}{c}\text { Reference } \\
\text { spots }\end{array}$ & & EphB3 & PYK & & & & & & & & PBS \\
\hline
\end{tabular}

B

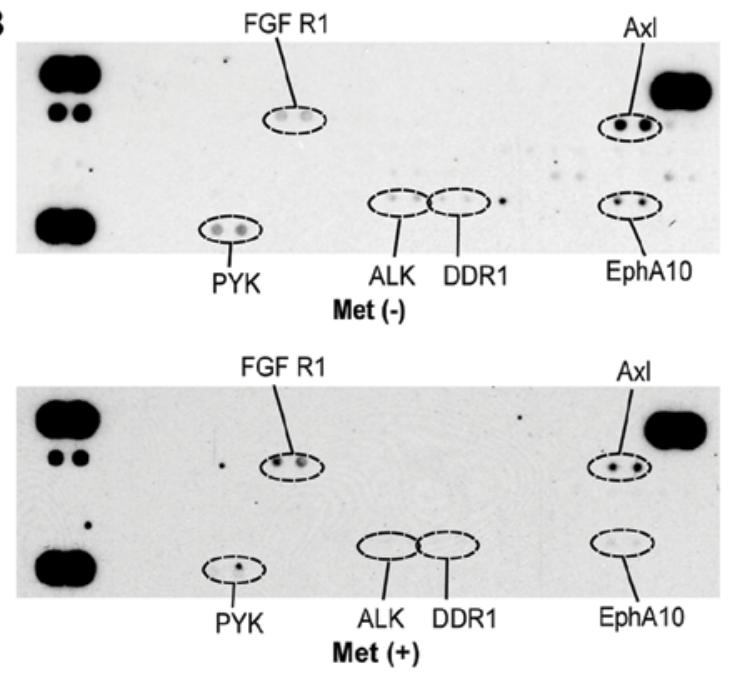

C

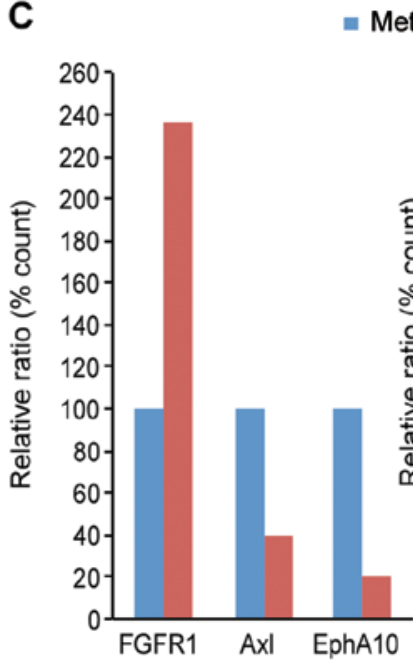

$\operatorname{Met}(-)=\operatorname{Met}(+)$

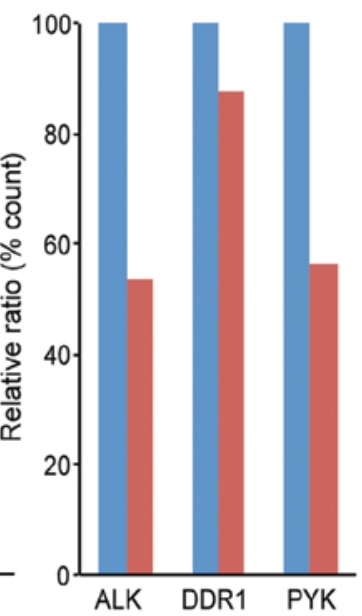

Figure 4. (A) The template indicates the locations of tyrosine kinase antibodies spotted onto a human phospho-RTK array. (B) Representative expression of various phosphorylated tyrosine kinase receptors in the HuCCT-1 cells treated with [Met (+)] or without [Met (-)] metformin at 48 h. (C) Densitometry indicated that the ratios of p-FGFR-1, Axl and EphA10 spots of metformin-treated to untreated cells were 236.5, 40.3, and 20.9\%, respectively. The densitometric ratios of p-ALK, DDR1, and PYK spots of metformin-treated to untreated cells were $53.7,87.9$ and $56.6 \%$, respectively.

p-AMPK $\alpha$ levels in the treated cells indicated AMPK pathway activation (Fig. 2B). However, no significant changes were identified in $\mathrm{p} 27^{\mathrm{kip} 1}$ expression (Fig. 2B).

To further investigate the mechanism of metformin action on HuCCT-1 cell proliferation, cell cycle progression was examined by flow cytometry. Following the addition of $10 \mathrm{mmol} / 1 \mathrm{metformin}$, an increasing number of cells began to accumulate in $\mathrm{G}_{0}-\mathrm{G}_{1}$, with $42.9 \%$ of cells in this phase after $24 \mathrm{~h}$ and $67.8 \%$ after $48 \mathrm{~h}$ (Fig. 3A). This finding was accompanied by reductions in the percentages of cells in the $S$ - and $\mathrm{G}_{2}-\mathrm{M}$ phases (Fig. 3B). These findings suggest that metformin inhibits cell cycle progression from $G_{0}-G_{1}$ into $S$ phase, which results in $\mathrm{G}_{1}$ cell cycle arrest.

Metformin affects $p$-RTKs in vitro. A p-RTK array system was used to identify the key RTKs associated with the antitumor effect of metformin. The use of an antibody array (Fig. 4A) enabled the expression of 49 activated RTKs to be screened in HuCCT-1 cells and tumors in the presence and absence of metformin. Metformin reduced the levels of expression of phosphorylated Axl, ALK, DDR1, EphA10, and PYK in vitro (Fig. 4B). In contrast, metformin increased the levels of expression of phosphorylated FGFR-1 (Fig. 4B).

Densitometric analysis indicated that the ratios of p-FGFR-1, Axl and EphA10 spots of metformin-treated to untreated cells were $236.5,40.3$ and $20.9 \%$, respec- tively (Fig. 4C). The densitometric ratios of p-ALK, DDR1 and PYK spots of metformin-treated to untreated cells were 53.7, 87.9 and $56.6 \%$, respectively (Fig. 4C).

Metformin does not affect angiogenesis-related molecules in vitro. An angiogenesis array system (Fig. 5A) was used to identify the key angiogenesis-related molecules associated with the antitumor effects of metformin on HuCCT-1 cells. The 20 screened angiogenesis molecules showed no change after metformin treatment (Fig. 5B).

Metformin inhibits tumor proliferation in vivo. To determine whether metformin affects tumor growth in vivo, nude mice were subcutaneously injected with HuCCT-1 cells, followed by an i.p. injection of metformin. Based on integrated tumor growth curves, the i.p. injection of metformin substantially inhibited tumor growth by $36 \%$ (Fig. 6) compared with the untreated control mice. Throughout this study, metformin had no apparent toxic effects on the mice and did not affect their body weight (data not shown). Furthermore, all animals survived throughout the experiment.

Metformin affects miRNA expression. Using a custom microarray platform, we analyzed the expression levels of 985 miRNA probes in tumor tissues in the presence and absence of metformin. The treatment of HuCCT-1 cells with 


\begin{tabular}{|c|c|c|c|c|c|c|c|}
\hline Positive & Positive & Negative & Negative & Angiogenin & EGF & ENA-78 & b FGF \\
\hline GRO & IFN- $\gamma$ & IGF-1 & IL-6 & IL-8 & LEPTIN & MCP-1 & PDGF-BB \\
\hline PIGF & RANTES & TGF- $\beta 1$ & TIMP-1 & TIMP-2 & Thrombopoietin & VEGF & VEGF-D \\
\hline & & & & & & Negative & Positive \\
\hline
\end{tabular}

B
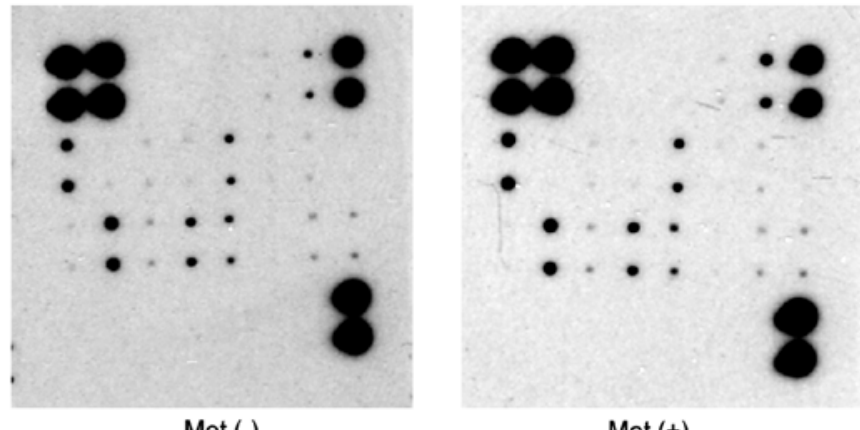

Met (+)

Figure 5. (A) The template indicates the location of angiogenesis-related proteins spotted onto a human angiogenesis array. (B) Representative expression of various angiogenesis-related proteins in HuCCT-1 cells treated with [Met (+)] or without [Met (-)] metformin. The 20 screened angiogenesis molecules did not exhibit changes following metformin treatment.

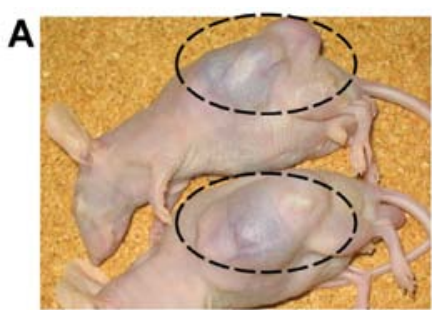

i) Control

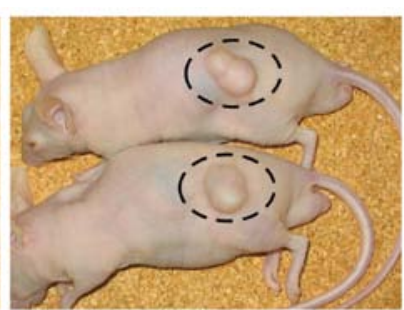

ii) Met $2 \mathrm{mg} /$ day

B

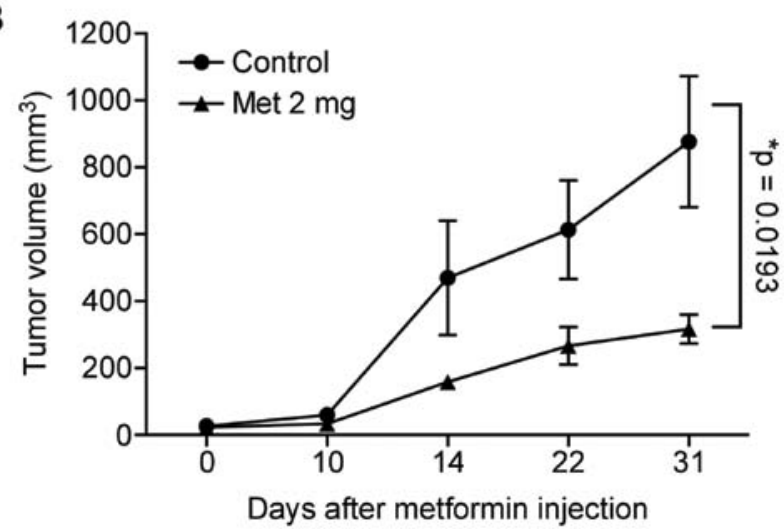

Figure 6. In vivo antitumor effects of metformin on established cholangiocarcinoma in nude mice. HuCCT-1 cells were subcutaneously implanted into the flanks of nude mice. When the tumors became palpable, 0 or $2 \mathrm{mg}$ of metformin (Met) was intraperitoneally injected for 31 days, 5 times per week. (A) Representative images of gross HuCCT-1 tumors from nude mice treated with i) vehicle or ii) $2 \mathrm{mg}$ of metformin. (B) Tumor growth curves in the control and metformin groups. Tumor volume $\left(\mathrm{mm}^{3}\right)$ was calculated as [tumor length $(\mathrm{mm}) \mathrm{x}$ tumor width $\left.(\mathrm{mm})^{2}\right] / 2$. The tumors were significantly smaller in the metformin-treated mice compared with those in the vehicle-treated mice. Each point represents the mean \pm standard deviation of 6 animals. "p=0.0193 by two-way ANOVA.

$10 \mathrm{mmol} / \mathrm{l}$ metformin for $48 \mathrm{~h}$ led to the significant upregulation of 14 miRNAs and the significant downregulation of 32 miRNAs (Table I, GEO, accession no. GSE71905).

Unsupervised hierarchical clustering analysis was conducted using Pearson's correlation, and the results indicated that tumor tissues treated with metformin in vivo clustered together and separately from the untreated cell lines (Fig. 7).

\section{Discussion}

CCA comprises hepatobiliary cancers with features of cholangiocyte differentiation, and these cancers can be anatomically classified as intrahepatic CCA (IHC), peripheral CCA (PHC), or distal CCA (DC) (20). For patients with CCA, PHC is the most common type (50\%), followed by DC (40\%) and 
Table I. Statistical results and chromosomal localizations of miRNAs in cholangiocarcinoma tumors treated with and without metformin.

\begin{tabular}{|c|c|c|c|}
\hline miRNA & Fold (treated/untreated) mean $\pm \mathrm{SD}$ & P-value & Chromosomal localization \\
\hline \multicolumn{4}{|l|}{ Upregulated } \\
\hline hsa-miR-1255b & $1.65 \pm 0.24$ & 0.000834578 & 4 \\
\hline hsa-miR-302d* & $1.65 \pm 0.25$ & 0.003518332 & $4 q 25$ \\
\hline hsa-miR-2355-3p & $1.63 \pm 0.52$ & 0.004281734 & 2 \\
\hline hsa-miR-3179 & $1.60 \pm 0.17$ & 0.006843565 & $16 \mathrm{p} 13.11$ \\
\hline hsa-miR-374a* & $1.48 \pm 0.18$ & 0.002117608 & $\mathrm{Xq} 13.2$ \\
\hline hsa-miR-516b & $1.46 \pm 0.29$ & 0.009460696 & $19 q 13.42$ \\
\hline hsa-miR-548w & $1.45 \pm 0.18$ & 0.004702519 & 16 \\
\hline hsa-miR-337-5p & $1.44 \pm 0.10$ & 0.000815099 & $14 q 32.2$ \\
\hline hsa-miR-302c* & $1.42 \pm 0.20$ & 0.004988631 & $4 q 25$ \\
\hline hsa-miR-502-3p & $1.41 \pm 0.19$ & 0.002896316 & $\mathrm{Xp} 11.23$ \\
\hline hsa-miR-3909 & $1.38 \pm 0.15$ & 0.001525238 & 22 \\
\hline hsa-miR-548f & $1.37 \pm 0.09$ & 0.001353683 & $10 q 21.1$ \\
\hline hsa-miR-325 & $1.31 \pm 0.11$ & 0.004195385 & $\mathrm{Xq} 21.1$ \\
\hline hsa-miR-4769-3p & $1.20 \pm 0.12$ & 0.009966157 & $\mathrm{X}$ \\
\hline \multicolumn{4}{|l|}{ Downregulated } \\
\hline hsa-miR-4688 & $0.42 \pm 0.06$ & 0.000146562 & 11 \\
\hline hsa-miR-3687 & $0.45 \pm 0.08$ & 0.00065697 & 21 \\
\hline hsa-miR-1184 & $0.45 \pm 0.19$ & 0.005703047 & $\mathrm{Xq} 28$ \\
\hline hsa-miR-4657 & $0.49 \pm 0.13$ & 0.000530843 & 7 \\
\hline hsa-miR-4504 & $0.49 \pm 0.10$ & 0.003397809 & 14 \\
\hline hsa-miR-3939 & $0.51 \pm 0.11$ & 0.001286193 & 6 \\
\hline hsa-miR-3672 & $0.53 \pm 0.22$ & 0.004121397 & $\mathrm{X}$ \\
\hline hsa-miR-4661-5p & $0.56 \pm 0.11$ & 0.002632183 & 8 \\
\hline hsa-miR-4648 & $0.59 \pm 0.05$ & 0.00000908 & 7 \\
\hline hsa-miR-4458 & $0.62 \pm 0.18$ & 0.00489108 & $5 \mathrm{p} 15.31$ \\
\hline hsa-miR-1273e & $0.62 \pm 0.07$ & 0.008277353 & \\
\hline hsa-miR-1290 & $0.63 \pm 0.12$ & 0.001296589 & 1 \\
\hline hsa-miR-943 & $0.63 \pm 0.09$ & 0.001483537 & $4 p 16.3$ \\
\hline hsa-miR-2392 & $0.64 \pm 0.08$ & 0.000387576 & 14 \\
\hline hsa-miR-4453 & $0.65 \pm 0.11$ & 0.007590261 & 4 \\
\hline hsa-miR-198 & $0.65 \pm 0.15$ & 0.003586389 & $3 q 13.33$ \\
\hline hsa-miR-2278 & $0.65 \pm 0.11$ & 0.008093878 & 9 \\
\hline hsa-miR-4669 & $0.65 \pm 0.12$ & 0.002037201 & 9 \\
\hline hsa-miR-4446-5p & $0.65 \pm 0.02$ & 0.000690821 & 3 \\
\hline hsa-miR-148a* & $0.67 \pm 0.06$ & 0.009282421 & $7 \mathrm{p} 15.2$ \\
\hline hsa-miR-4646-5p & $0.68 \pm 0.10$ & 0.007048367 & 6 \\
\hline hsa-miR-4801 & $0.68 \pm 0.10$ & 0.009396036 & 4 \\
\hline hsa-miR-16-1* & $0.68 \pm 0.11$ & 0.008889364 & $13 q 14.2$ \\
\hline hsa-miR-3192 & $0.69 \pm 0.09$ & 0.001444872 & 20 \\
\hline hsa-miR-4701-5p & $0.70 \pm 0.13$ & 0.004496297 & 12 \\
\hline hsa-miR-4758-3p & $0.72 \pm 0.05$ & 0.003096462 & 20 \\
\hline hsa-miR-492 & $0.72 \pm 0.10$ & 0.003373891 & $12 q 22$ \\
\hline hsa-miR-4705 & $0.72 \pm 0.11$ & 0.002282486 & 13 \\
\hline hsa-miR-99b* & $0.74 \pm 0.09$ & 0.005430911 & $19 q 13.41$ \\
\hline hsa-miR-4800-3p & $0.75 \pm 0.12$ & 0.008683947 & 4 \\
\hline hsa-miR-4665-3p & $0.76 \pm 0.12$ & 0.004807288 & 9 \\
\hline hsa-miR-4436a & $0.76 \pm 0.05$ & 0.001374976 & 2 \\
\hline
\end{tabular}




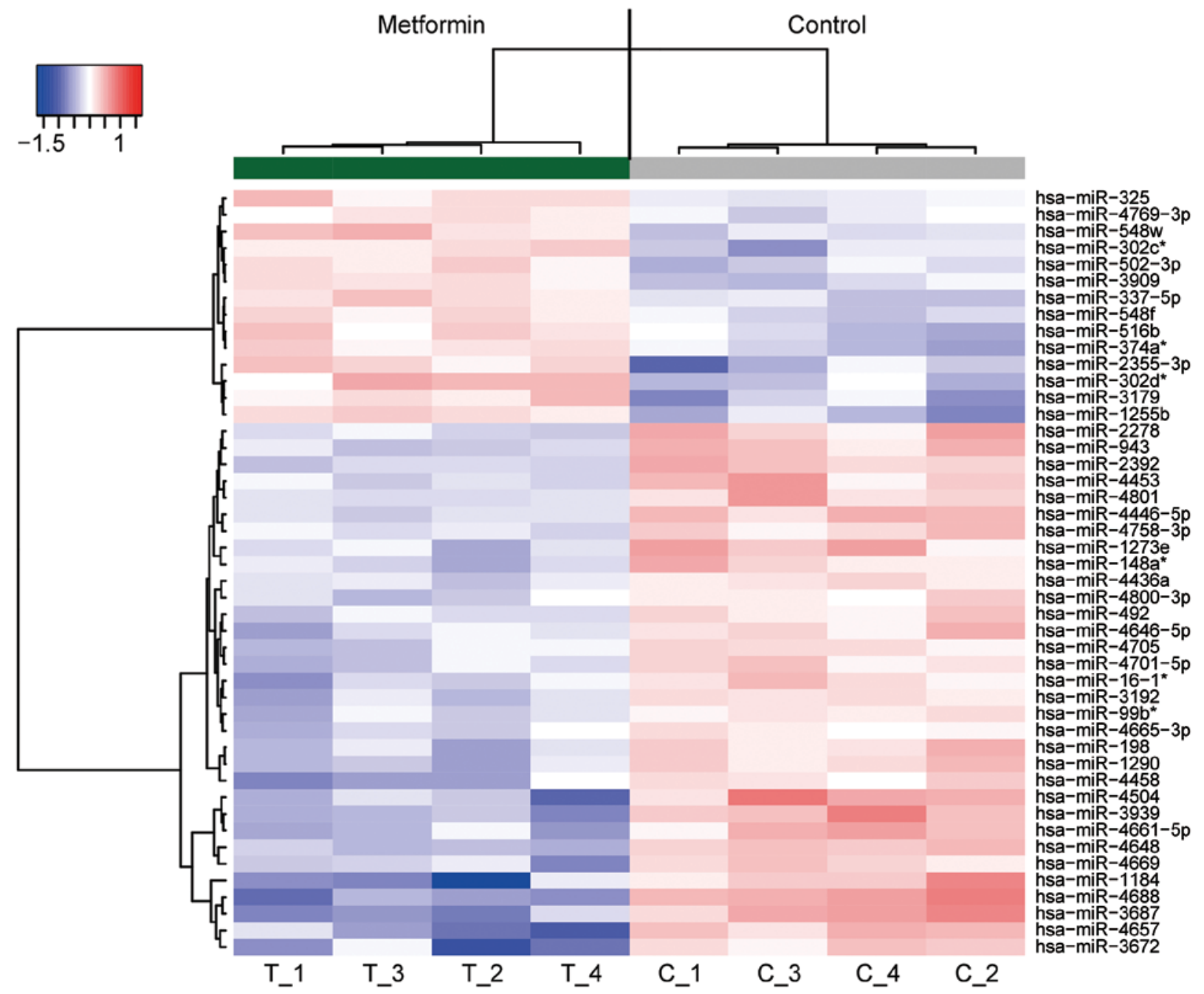

Figure 7. Hierarchical clustering of tumor samples from a xenograft animal model with and without metformin. Tumorous tissues were clustered according to the expression profiles of 46 differentially expressed miRNAs between tumorous tissues with and without metformin treatment. The analyzed samples are shown in the columns, and the miRNAs are presented in the rows. The miRNA clustering color scale shown at the top indicates the relative expression levels of miRNAs, and red and blue represent high and low expression levels, respectively.

IHC (10\%) (21). The incidence and mortality of IHC have increased over the previous 3 decades $(20,22)$ as most patients with biliary malignancies have locally advanced or distal metastatic disease at the time of presentation (23).

Metformin (dimethylbiguanide) is one of the most commonly prescribed anti-hyperglycemic drugs for the treatment of type 2 diabetes worldwide. The mechanism of action of metformin includes the stimulation of glucose uptake and an increase in fatty acid oxidation in the muscles and liver (5). The most common side effects of metformin are mainly gastrointestinal symptoms, including abdominal discomfort, a metallic taste, and mild anorexia (24). These symptoms are usually mild and reversible after dose reduction or discontinuation of the drug. Lactic acidosis is well known to be a serious metabolic complication that can occur because of metformin accumulation during treatment with metformin. However, the incidence of it in metformin users appears to be very low (25). Drug-related bone marrow suppression occurs in patients treated with other cell cycle and checkpoint inhibitors such as azathioprine, cyclophosphamide and methotrexate. On the other hand, metformin has less side effects compared to these drugs.
These properties can result in inhibition of cancer cell growth, suppression of HER2 overexpression and inhibition of mTOR (26-28). Additionally, a recent study examining the risk factors for intrahepatic CCA development has emphasized the association between metformin use and a reduction in the incidence of this disease in patients with diabetes (29). This finding is biologically plausible as the mTOR signaling pathway, which is a pharmacological target of metformin, is part of the CCA oncogenic network (30). Thus, metformin use may be chemopreventive, indicating the need for prospective studies, especially if a high-risk group can be identified (a genetically high-risk population with primary sclerosing cholangitis) (30).

Metformin has also been demonstrated to block cancer cell proliferation $(5,10-13)$ and reduce the risk of esophageal, stomach, colon, pancreatic and liver cancer, as well as improve cancer prognosis in patients with type 2 diabetes (31).

Metformin has been previously demonstrated to inhibit cell proliferation and enhance the chemosensitivity of CCA cell lines (32). However, the antitumor effect of metformin and the association of microRNAs on CCA have remained 
unknown. Here, we demonstrated that metformin is not only a potent inhibitor of human CCA cell growth but also inhibited tumorigenesis in a xenograft model.

Specific cyclin/Cdk complexes are activated at different intervals during the cell cycle. Complexes of Cdk4 and Cdk6 with cyclin D1 are required for $\mathrm{G}_{1}$ phase progression, whereas complexes of Cdk2 with cyclin $E$ are required for $G_{1}$ to $S$ transition (33). Metformin has been demonstrated to downregulate cyclin D1 in various cancer cell lines, including stomach (11), colon (10), liver (13), breast (9) and prostate (5) cancer lines. The findings presented here indicate that these major cell cycle regulators (cyclin D1, Cdk4, and phosphorylated $\mathrm{Rb}$ ) may be intracellular targets of the metformin-mediated anti-proliferative effect in human CCA cell lines. Additionally, AMPK activation causes cell cycle arrest associated with the stabilization of p53 and the cyclin-dependent kinase inhibitor p21 ${ }^{\mathrm{WAF} 1}$ and p27 ${ }^{\mathrm{kip} 1}$ (34-36). Furthermore, CDK inhibitors, such as p21 and p27, have been demonstrated to play an important role in the inhibitory effects of metformin in previous studies $(37,38)$. In the present study, increased p-AMPK $\alpha$ levels in treated cells indicated AMPK pathway activation. However, we did not identify significant changes in $\mathrm{p} 27^{\mathrm{kip} 1}$ protein in the HuCCT-1 cells.

In addition, flow cytometry indicated that metformin arrested CCA cells at the $\mathrm{G}_{0}$ to $\mathrm{G}_{1}$ transition in vitro. These data suggest that the antitumor effect of metformin may be related to the reduction of various cell cycle-related proteins, especially cyclin D1. The expression of various cell cycle-related molecules, including cyclin D1, Cdk4, Cdk6, cyclin E and Cdk2, are enhanced in various types of cancers $(39,40)$. Therefore, the inhibition of these molecules, including cyclin D1, may be the present target for controlling tumor proliferation.

Metformin has been demonstrated to alter the phosphorylation of various proteins, including Akt, $\beta$-catenin, CREB, Chk2 (41) and c-Src (33), in various cell lines. Using protein arrays, we determined that metformin reduced the expression levels of phosphorylated Axl, EphA10, ALK, and PYK in CCA cells. However, 20 screened angiogenesis molecules did not exhibit changes following metformin treatment in human CCA cell lines.

The miRNAs associated with the antitumor effects of metformin were assessed using miRNA expression arrays. miRNAs are small, endogenous, non-coding ssRNAs that are 21-30 nucleotides in length and modulate the expression of various target genes at the post-transcriptional and translational levels (42). In this study, cluster analyses clearly indicated that metformin treatment affected the extent of miRNA expression in the clustered cells. We identified 46 miRNAs that were differentially expressed in clusters. These miRNAs are meaningful candidates to gauge the effectiveness of metformin treatment and provide clues regarding the molecular basis of its anticancer effects, particularly those mediated by miRNAs. We found that members of the miR-302 were upregulated in tumorous tissues treated with metformin. Human miR-302 cluster cording region is located on chrosome 4 and contains nine different miRNAs (43). miR-302 is specifically expressed in human embryonic stem cells, and is involved in the regulation of cell cycle genes (44). miR-302 inhibited the proliferation and tumorigenicity of endometrial cancer cells by inhibiting the gene expression of cyclin D1 and CDK1 (45). Additionally, Jiang et al reported that six miRNAs (mir124, 182, 27b, let7b, 221 and 181a), which could directly target cell cycle-regulating genes, was altered by metformin in in vitro and in vivo studies in human CCA (46).

In conclusion, our findings indicate that metformin inhibits human CCA cell proliferation and tumor growth, potentially via the suppression of cell cycle-related molecules through miRNA alterations.

\section{Acknowledgements}

We thank Ms Kana Ogawa and Ms Keiko Fujikawa for providing technical assistance. This study was supported with an unrestricted grant by AstraZeneca Japan.

\section{References}

1. Welzel TM, McGlynn KA, Hsing AW, O'Brien TR and Pfeiffer RM: Impact of classification of hilar cholangiocarcinomas (Klatskin tumors) on the incidence of intra- and extrahepatic cholangiocarcinoma in the United States. J Natl Cancer Inst 98: 873-875, 2006.

2. Khan SA, Davidson BR, Goldin RD, Heaton N, Karani J, Pereira SP, Rosenberg WM, Tait P, Taylor-Robinson SD, Thillainayagam AV, et al; British Society of Gastroenterology: Guidelines for the diagnosis and treatment of cholangiocarcinoma: An update. Gut 61: 1657-1669, 2012.

3. Everhart JE and Ruhl CE: Burden of digestive diseases in the United States Part III: Liver, biliary tract, and pancreas. Gastroenterology 136: 1134-1144, 2009.

4. Tyson GL and El-Serag HB: Risk factors for cholangiocarcinoma. Hepatology 54: 173-184, 2011.

5. Ben Sahra I, Laurent K, Loubat A, Giorgetti-Peraldi S, Colosetti P, Auberger P, Tanti JF, Le Marchand-Brustel Y and Bost F: The antidiabetic drug metformin exerts an antitumoral effect in vitro and in vivo through a decrease of cyclin D1 level. Oncogene 27: 3576-3586, 2008.

6. Libby G, Donnelly LA, Donnan PT, Alessi DR, Morris AD and Evans JM: New users of metformin are at low risk of incident cancer: A cohort study among people with type 2 diabetes. Diabetes Care 32: 1620-1625, 2009.

7. Landman GW, Kleefstra N, van Hateren KJ, Groenier KH, Gans RO and Bilo HJ: Metformin associated with lower cancer mortality in type 2 diabetes: ZODIAC-16. Diabetes Care 33: 322-326, 2010.

8. Kourelis TV and Siegel RD: Metformin and cancer: New applications for an old drug. Med Oncol 29: 1314-1327, 2012.

9. Anisimov VN, Egormin PA, Piskunova TS, Popovich IG, Tyndyk ML, Yurova MN, Zabezhinski MA, Anikin IV, Karkach AS and Romanyukha AA: Metformin extends life span of HER-2/neu transgenic mice and in combination with melatonin inhibits growth of transplantable tumors in vivo. Cell Cycle 9: 188-197, 2010.

10. Zhou XZ, Xue YM, Zhu B and Sha JP: Effects of metformin on proliferation of human colon carcinoma cell line SW-480. Nan Fang Yi Ke Da Xue Xue Bao 30: 1935-1938, 2010 (In Chinese).

11. Kato K, Gong J, Iwama H, Kitanaka A, Tani J, Miyoshi H, Nomura K, Mimura S, Kobayashi M, Aritomo Y, et al: The antidiabetic drug metformin inhibits gastric cancer cell proliferation in vitro and in vivo. Mol Cancer Ther 11: 549-560, 2012.

12. Kobayashi M, Kato K, Iwama H, Fujihara S, Nishiyama N, Mimura S, Toyota Y, Nomura T, Nomura K, Tani J, et al: Antitumor effect of metformin in esophageal cancer: In vitro study. Int J Oncol 42: 517-524, 2013.

13. Fujihara S, Kato K, Morishita A, Iwama H, Nishioka T, Chiyo T, Nishiyama N, Miyoshi H, Kobayashi M, Kobara H, et al: Antidiabetic drug metformin inhibits esophageal adenocarcinoma cell proliferation in vitro and in vivo. Int $\mathrm{J}$ Oncol 46: 2172-2180, 2015.

14. Miyoshi H, Kato K, Iwama H, Maeda E, Sakamoto T, Fujita K, Toyota Y, Tani J, Nomura T, Mimura S, et al: Effect of the anti-diabetic drug metformin in hepatocellular carcinoma in vitro and in vivo. Int J Oncol 45: 322-332, 2014. 
15. Masaki T, Tokuda M, Yoshida S, Nakai S, Morishita A, Uchida N, Funaki T, Kita Y, Funakoshi F, Nonomura T, et al: Comparison study of the expressions of myristoylated alaninerich $\mathrm{C}$ kinase substrate in hepatocellular carcinoma, liver cirrhosis, chronic hepatitis, and normal liver. Int J Oncol 26 : 661-671, 2005.

16. Bradford MM: A rapid and sensitive method for the quantitation of microgram quantities of protein utilizing the principle of protein-dye binding. Anal Biochem 72: 248-254, 1976.

17. Laemmli UK: Cleavage of structural proteins during the assembly of the head of bacteriophage T4. Nature 227: 680-685, 1970.

18. Towbin H, Staehelin T and Gordon J: Electrophoretic transfer of proteins from polyacrylamide gels to nitrocellulose sheets: Procedure and some applications. Proc Natl Acad Sci USA 76: 4350-4354, 1979.

19. D'Incalci M, Colombo T, Ubezio P, Nicoletti I, Giavazzi R, Erba E, Ferrarese L, Meco D, Riccardi R, Sessa C, et al: The combination of yondelis and cisplatin is synergistic against human tumor xenografts. Eur J Cancer 39: 1920-1926, 2003.

20. Rizvi S and Gores GJ: Pathogenesis, diagnosis, and management of cholangiocarcinoma. Gastroenterology 145: 1215-1229, 2013.

21. DeOliveira ML, Cunningham SC, Cameron JL, Kamangar F, Winter JM, Lillemoe KD, Choti MA, Yeo CJ and Schulick RD: Cholangiocarcinoma: Thirty-one-year experience with 564 patients at a single institution. Ann Surg 245: 755-762, 2007.

22. Patel T: Increasing incidence and mortality of primary intrahepatic cholangiocarcinoma in the United States. Hepatology 33 1353-1357, 2001.

23. Hezel AF and Zhu AX: Systemic therapy for biliary tract cancers. Oncologist 13: 415-423, 2008.

24. Bailey CJ and Turner RC: Metformin. N Engl J Med 334: 574-579, 1996

25. Stang M, Wysowski DK and Butler-Jones D: Incidence of lactic acidosis in metformin users. Diabetes Care 22: 925-927, 1999.

26. Alimova IN, Liu B, Fan Z, Edgerton SM, Dillon T, Lind SE and Thor AD: Metformin inhibits breast cancer cell growth, colony formation and induces cell cycle arrest in vitro. Cell Cycle 8 : 909-915, 2009

27. Vazquez-Martin A, Oliveras-Ferraros C and Menendez JA: The antidiabetic drug metformin suppresses HER2 (erbB-2) oncoprotein overexpression via inhibition of the mTOR effector p70S6K1 in human breast carcinoma cells. Cell Cycle 8: 88-96, 2009.

28. Vázquez-Martín A, Oliveras-Ferraros C, del Barco S Martín-Castillo B and Menéndez JA: mTOR inhibitors and the anti-diabetic biguanide metformin: New insights into the molecular management of breast cancer resistance to the HER2 tyrosine kinase inhibitor lapatinib (Tykerb). Clin Trans Oncol 11: 455-459, 2009

29. Chaiteerakij R, Yang JD, Harmsen WS, Slettedahl SW, Mettler TA, Fredericksen ZS, Kim WR, Gores GJ, Roberts RO, Olson JE, et al: Risk factors for intrahepatic cholangiocarcinoma: Association between metformin use and reduced cancer risk. Hepatology 57: 648-655, 2013.

30. Razumilava $\mathrm{N}$ and Gores GJ: Cholangiocarcinoma. Lancet 383: 2168-2179, 2014

31. Franciosi M, Lucisano G, Lapice E, Strippoli GF, Pellegrini F and Nicolucci A: Metformin therapy and risk of cancer in patients with type 2 diabetes: Systematic review. PLoS One 8: e71583, 2013.
32. Ling S, Feng T, Ke Q, Fan N, Li L, Li Z, Dong C, Wang C, $\mathrm{Xu}$ F, Li Y, et al: Metformin inhibits proliferation and enhances chemosensitivity of intrahepatic cholangiocarcinoma cell lines. Oncol Rep 31: 2611-2618, 2014.

33. Masaki T, Shiratori Y, Rengifo W, Igarashi K, Yamagata M, Kurokohchi K, Uchida N, Miyauchi Y, Yoshiji H, Watanabe S, et al: Cyclins and cyclin-dependent kinases: Comparative study of hepatocellular carcinoma versus cirrhosis. Hepatology 37: $534-543,2003$

34. Imamura K, Ogura T, Kishimoto A, Kaminishi $M$ and Esumi H: Cell cycle regulation via p53 phosphorylation by a 5'-AMP activated protein kinase activator, 5-aminoimidazole- 4-carboxamide-1-beta-D-ribofuranoside, in a human hepatocellular carcinoma cell line. Biochem Biophys Res Commun 287: 562-567, 2001

35. Jones RG, Plas DR, Kubek S, Buzzai M, Mu J, Xu Y, Birnbaum MJ and Thompson CB: AMP-activated protein kinase induces a p53-dependent metabolic checkpoint. Mol Cell 18: 283-293, 2005.

36. Liang J, Shao SH, Xu ZX, Hennessy B, Ding Z, Larrea M, Kondo S, Dumont DJ, Gutterman JU, Walker CL, et al: The energy sensing LKB1-AMPK pathway regulates p27(kip1) phosphorylation mediating the decision to enter autophagy or apoptosis. Nat Cell Biol 9: 218-224, 2007.

37. Zhuang Y and Miskimins WK: Cell cycle arrest in metformin treated breast cancer cells involves activation of AMPK, downregulation of cyclin $\mathrm{D} 1$, and requires $\mathrm{p} 27^{\mathrm{Kipl}}$ or $\mathrm{p} 21^{\mathrm{Cip} 1}$. $\mathrm{J}$ Mol Signal 3: 18, 2008.

38. Rocha GZ, Dias MM, Ropelle ER, Osório-Costa F, Rossato FA, Vercesi AE, Saad MJ and Carvalheira JB: Metformin amplifies chemotherapy-induced AMPK activation and antitumoral growth. Clin Cancer Res 17: 3993-4005, 2011.

39. Han S, Kim HY, Park K, Lee MS, Kim HJ and Kim YD Expression of p27Kip1 and cyclin D1 proteins is inversely correlated and is associated with poor clinical outcome in human gastric cancer. J Surg Oncol 71: 147-154, 1999.

40. Aoyagi K, Koufuji K, Yano S, Murakami N, Terasaki Y, Yamasaki Y, Takeda J, Tanaka M and Shirouzu K: Immunohistochemical study on the expression of cyclin D1 and E in gastric cancer. Kurume Med J 47: 199-203, 2000.

41. Vazquez-Martin A, Oliveras-Ferraros C,CufíS, Martin-CastilloB and Menendez JA: Metformin activates an ataxia telangiectasia mutated (ATM)/Chk2-regulated DNA damage-like response. Cell Cycle 10: 1499-1501, 2011

42. Morishita A and Masaki T: miRNA in hepatocellular carcinoma. Hepatol Res 45: 128-141, 2015.

43. Barroso-del Jesus A, Lucena-Aguilar G and Menendez P: The miR-302-367 cluster as a potential stemness regulator in ESCs. Cell Cycle 8: 394-398, 2009.

44. Card DA, Hebbar PB, Li L, Trotter KW, Komatsu Y, Mishina Y and Archer TK: Oct4/Sox2-regulated miR-302 targets cyclin D1 in human embryonic stem cells. Mol Cell Biol 28: 6426-6438, 2008.

45. Yan GJ, Yu F, Wang B, Zhou HJ, Ge QY, Su J, Hu YL, Sun HX and Ding LJ: MicroRNA miR-302 inhibits the tumorigenicity of endometrial cancer cells by suppression of cyclin D1 and CDK1. Cancer Lett 345: 39-47, 2014.

46. Jiang X, Ma N, Wang D, LiF, He R, Li D, Zhao R, Zhou Q, Wang Y, Zhang F, et al: Metformin inhibits tumor growth by regulating multiple miRNAs in human cholangiocarcinoma. Oncotarget 6 : 3178-3194, 2015. 